Quite apart from their authoritative review of the Earth's history, the authors have captured much of the fun, the excitement, the doubts, the frustrations and the satisfactions of scientists who devote their lives to unravelling one aspect or another of the Earth's fascinating history. Having so subtly woven this human interest into the history and development of one of the boldest theories ever to come true, they should not be surprised to find, in the years to come, that they have drawn into the fraternity of Earth scientists many able young minds.

Debate About the Earth will be stimulating to a broad spectrum of students, and it will be useful to the profossional geologist as a means of catching up with important and sitrtling developments in the fundamentals of his science. The authors obviously enjoyed a happy relationship with the publishers.

W. H. Bradley

\section{NEW PHYSICS SUMMER SCHOOL}

\section{Recent Developments in Particle Physics}

Edited by Michael Moravesik. (Proceedings of the First Pacific International Summer School in Physics, August 1965.) (Nuclear Physics, Vol. 3.) Pp. viii + 263. (New York: Gordon and Breach Science Publishers, 1966. Distributed in the UK by Blackie and Son, Ltd.) $\$ 15$.

The University of Hawaii at Honolulu has now joined the ever expanding host of institutions which sponsor a vacation school or institute in some advanced area of research. They should not find much difficulty in recruiting the lecturers, but the student body is likely to remain confined to the Pacific seaboard of the United States. Thus the printed version of the lecture notes will be all the more valuable in Europe.

Proceedings of the first school in 1965 contain notes on "Particles and Cross Sections in a Theory of Local Observables", by R. Haag; "Spontaneous Symmetry Breaking and Related Problems", by H. Miyazawa; "The Algebraic Description of Hadron Matter and its Observational Implications", by Y. Neeman; "Lectures on Bootstraps", by F. Zachariasen; "The Bootstrap Theory of Symmetry Breaking", by S. Frautschi; and "The Non-Dynamical Structure of Particle Reactions", by M. Moravcsik. These are all self-contained, concise expositions, a few overtaken by more recent developments. The most valuable are those by Haag, Miyazawa and Moravesik. Zachariasen gave the same lectures later that year in Vienna and they have appeared in print before. By the way of preface there is a most amusing and yet convincing apologia for this kind of school by the director, M. Moravesik.

The volume is a paperback and the price seems excessive. S. Zienau

\section{SEMICONDUCTOR SURFACES}

\section{Electrical Properties of Semiconductor Surfaces}

By Daniel R. Frankl. (International Series of Monographs on Semiconductors, Vol. 7.) Pp. $x v+310$. (Oxford, London and New York: Pergamon Press Ltd., 1967.) 84s. net.

THE extent to which the electrical properties of a semiconductor are dependent on the physical and chemical conditions of its surface has been the subject of much experimental study during the past twenty years, largely prompted by the technical requirement to control and stabilize the performance of semiconductor devices. There have been corresponding advances in theoretical understanding, and much previously empirical knowledge has now been rationalized, leading to useful insight and prediction.
The literature of research on semiconductor surfaces is widely scattered except for the proceedings of topical conferences and symposia, so that the appearance of this up to date text is specially welcome. The book succeeds in its aim of being largely self contained by presenting a thorough treatment of the theoretical background necessary to interpret the experimental data. The first two chapters discuss the equilibrium distributions of electrons and ions in bulk intrinsic and extrinsic semiconductors and in their surface space-charge layers. The next chapter deals with non-equilibrium conditions arising from illumination or carrier injection and considers both the final steady state and the rolaxation spectrum. The fourth chapter treats field effects in great detail as befits the experimental importance of the topic, and the related theory is competently and critically presented.

The second half of the book is devoted to surface preparations and to the surface states resulting from them. There is shown to be little relation between observed surface states and those derived from the idealized theoretical models of Tamm and of Shockley. Experimental data are presented in considerable detail together with descriptions of methods of measurement and interpretation. Germanium and silicon receive by far the greatest attention as would be expected from the extensive study already devoted to their bulk properties which is a prerequisite for an understanding of the surface data. The available fragmentary data on GaAs, InSb, $\mathrm{ZnO}, \mathrm{CdS}$ and $\mathrm{PbS}$ are also collected.

This book conveys the impression throughout of being well organized and critically written. It will be useful to research workers both as a text and a reference. The bibliography is copious and continues through 1966. The style is eminently readable, but it can only be a matter of conjecture whether the excessive use of commas should be attributed to the author or to an enthusiastic copy editor. Misprints are few and when they occur in the equations they are readily corrected by the alert reader.

R. E. BuRgess

\section{RIGOUR AND THE CALCULUS}

\section{Differential and Integral Calculus}

By Friedhelm Erwe. Translated by B. Fishel. Pp. $x+494$. (Edinburgh and London: Oliver and Boyd, Ltd., 1967.) 57s. $6 d$. net.

THere are many books on the differential and integral calculus. What justifies the appearance of another one? The present book differs from many in the rigour with which the subject matter is developed. It is not a collection of recipes and formulae, deduced largely by an appeal to intuition or experience of the physical world. Instead, it is "pure" from the start, and it is a long way to the introduction of the calculus. Continuity and differentiation are introduced only after ninety pages of preliminary material about real numbers and infinite processes. After that there is a careful development of the usual topies covered in a good course on the differential calculus. This is followed by a fairly easy chapter on the elementary functions. Integration is not the next topic to be treated. Instead, the author proceeds to a rigorous discussion of the differential calculus in the case of two or more variables. This discussion includes a long section on curves, and the definition used for a curve "admits entitics which defy the possibility of geometrical visualization". The section closes with a statement of the Jordan curve theorem, and it is something of an anticlimax for us to learn that "its rigorous proof goes very deep and because of its length we shall have to omit it". Of course, the reason is that the proof lies buried in topology, and that is another story. 